\title{
Carlos Pastore y "el general de la virgen espada”. Memoria y destino nacional en Paraguay
}

Tomás Sansón Corbo*

Recibido el 19 de agosto de 2019; aceptado el 15 de mayo de 2020

\section{RESUMEN}

Carlos Pastore Goiburu (1907-1996) fue un destacado intelectual paraguayo, afiliado al Partido Liberal, quien utilizó el conocimiento histórico como instrumento de lucha política y de resistencia ideológica. Durante su exilio montevideano publicó dos obras emblemáticas: El Paraguay y la tiranía de Morínigo (1947) y La lucha por la tierra en el Paraguay (1949). En ellas dejó testimonio de su militancia contra la dictadura que imperaba en su país y procuró explicar algunos de sus problemas estructurales. Mantuvo vínculos epistolares con intelectuales y políticos contemporáneos. En ese intercambio de correspondencia pueden rastrearse sus convicciones historiográficas.

El objetivo de este artículo es analizar el pensamiento de Pastore sobre la escritura de la historia y sobre los usos políticos del pasado en el contexto de la producción de los intelectuales liberales en el exilio. Pretendo hacerlo a través del examen de una extensa carta de Pastore remitida al coronel Arturo Bray en 1959, cuya copia se conserva en su archivo privado, custodiado en la Academia Paraguaya de la Historia. El estudio de esa misiva permite conocer el pensamiento de los historiadores liberales sobre el nacionalismo excluyente de Juan O’Leary y revela las estrategias discursivas e ideológicas implementadas para enfrentarlo.

Palabras clave: Historiografía, Paraguay, liberales, dictadura, Carlos Pastore.

* Universidad de la República, Montevideo, Uruguay. Correo electrónico: slbt@hotmail.com 


\section{Carlos Pastore and "The general of the Virgin Sword". Memory and national destiny in Paraguay}

\section{Abstract}

Carlos Pastore Goiburu (1907- 1996) was an outstanding Paraguayan intellectual, affiliated to the Liberal Party, who used the historical knowledge as an instrument of political fight and of ideological resistance. During his exile in Montevideo he published two emblematic works: El Paraguay y la tiranía de Morínigo (1947) and La lucha por la tierra en el Paraguay (1949). In them he left testimony of his militancy against the dictatorship that was reigning in his country and tried to explain some of its structural matters. He supported epistolary links with intellectual and contemporary politicians. In this exchange of correspondence, his historiographical convictions can be traced.

The aim of this article is to analyze Pastore's thought on the writing of the history and on the political uses of the past in the context of the production of the intellectual liberals in the exile. I try to do it across the examination of Pastore's extensive letter sent to the colonel Arturo Bray in 1959, whose copy remains in his private file guarded in the Paraguayan Academy of History. The study of this missive allows us to know the thought of liberal historians about the exclusionary nationalism of Juan O'Leary and reveals the discursive and ideological strategies leaded to face it.

Key words: Historiography, Paraguay, liberals, dictatorship, Carlos Pastore.

\section{INTRODUCCIÓN}

Carlos Pastore nació en Mbuyapey en 1907 y falleció en Asunción en 1996. Fue un destacado jurista, político e historiador paraguayo. Tuvo una larga y activa militancia en el Partido Liberal de su país.

Estudió en el Colegio Nacional de la capital y se graduó de abogado y escribano en la UNA. Comenzó tempranamente su actividad en la función pública como subsecretario de la presidencia en la administración de José Patricio Guggiari (1928-1932). Durante la Guerra del Chaco (1932-1935) se desempeñó como Jefe de la Sección Correos y Claves del Comando. En 1939 fue designado director del Departamento de Tierras y Colonización por el presidente José Félix Estigarribia (1939-1940). En el desempeño de ese cargo conoció en profundidad la situación de la propiedad de la tierra en el Paraguay y las condiciones de vida de los campesinos. Luego de la muerte de Estigarribia (1940) debió abandonar el país. 
Se radicó en Montevideo donde permaneció varias décadas. Protagonizó un efímero retorno en 1947 y "numerosos intentos de ingresar oficialmente" en la década de 1960, "todos frustrados por la dictadura, que lo detenía y expulsaba de forma sistemática". ${ }^{1}$

En la capital uruguaya ejerció su profesión de abogado y desarrolló una intensa actividad periodística y política. Se relacionó con personalidades destacadas de la cultura y de la política oriental (Ariosto González, Arturo Ardao y Luis Batlle Berres, entre otros). Fue nombrado miembro correspondiente del Instituto Histórico y Geográfico del Uruguay. En 1948 fue iniciado en la masonería uruguaya.

Militó activamente contra los gobiernos autoritarios de su país. Esa actividad lo obligaba a viajar frecuentemente a Buenos Aires y a diversas provincias argentinas. En radio Ariel de Montevideo condujo el programa $\mathrm{La}$ hora de la liberación paraguaya. En 1947 publicó El Paraguay y la tiranía de Morínigo (Montevideo, 1947), obra en la que difundió varias de "esas audiciones, desenvueltas sobre la base de las notas redactadas y leídas entre el 31 de enero y el 7 de agosto de 1946". ${ }^{2}$

Se dedicó con ahínco a la investigación histórica. Publicó un trabajo emblemático, La lucha por la tierra en el Paraguay (Montevideo, 1949). Es una obra documentada en la que expone su interpretación sobre las políticas públicas relacionadas con la tierra y las modalidades de acceso a la misma. ${ }^{3}$ La primera edición apareció en 1949 y la segunda en 1972 (considerablemente corregida y aumentada).

Pastore Olmedo, "Semblanza biográfica del Dr. Carlos Pastore Goiburu”, p. 27.

Brezzo, "Reconstruyendo a Carlos Pastore: objetivos para una biografía intelectual”, p. 49.

En este libro Carlos Pastore realiza un ejercicio explicativo de las claves esenciales para comprender uno de los problemas socioeconómicos de mayor trascendencia de la historia guaraní. El trabajo está estructurado en tres grandes partes: "Época del coloniaje (15371811)”, “Época de la Independencia (1811-1870)” y “Época constitucional (1870-1948)”. Cada una es interpretada desde una preceptiva crítica que en ciertos aspectos parece producir una reverberación de los estertores el El dolor paraguayo de Rafael Barret. En la "Época de la Independencia”, la centralidad del relato la ocupa Carlos Antonio López. El autor plantea que durante su administración, la distribución de tierras estuvo orientada "por los principios del mercantilismo de Estado" (Pastore, La lucha por la tierra en el Paraguay, p. 80). Se introduce este concepto - uno de los que "más debates provocaría entre los lectores" (Brezzo, "Reconstruyendo a Carlos Pastore: objetivos para una biografía intelectual”, p. 54), según Liliana Brezzo - para explicar el "constante aumento del patrimonio del Estado, sobre la base del desconocimiento del derecho de los particulares sobre sus bienes" (Pastore, 1949: 80). La estructura económica, social y política del gobierno de don Carlos es examinada — como toda la historia paraguaya - desde una doble perspectiva: por un lado, se contextualizan en el espacio regional platense las iniciativas y medidas gubernativas, atendiendo en particular a la influencia que sobre la cuestión de la propiedad de la tierra podrían ejercer los factores geopolíticos en pugna; por otro, se tienen en cuenta los intereses y las contradicciones de clase que incidían en la adopción de ciertas medidas. 
Regresó a Paraguay a fines de la década de 1970. Durante la etapa final de su vida estuvo bajo estrecha vigilancia por agentes del régimen stronista. Falleció en 1996.

En la Academia Paraguaya de la Historia, en Asunción, se custodia la “Colección Bibliográfica y Documental Carlos Pastore”. El fondo conserva, entre otros materiales, el archivo personal del intelectual y una importante colección de folletos. Una de las series más valiosas es el epistolario que contiene información muy variada tanto sobre la vida, obra y pensamiento de Pastore, como sobre la política, la historia y la historiografía de Paraguay. Entre las copias de las cartas enviadas por Pastore hay una de 1959, remitida al coronel Arturo Bray, que reviste particular importancia. Se trata de una misiva mecanografiada, de diez fojas y texto abigarrado, en las que el historiador y jurista realiza una serie de reflexiones relacionadas con la historiografía paraguaya en general y con las interpretaciones sobre el rol del mariscal Francisco Solano López en particular. Parece escrita con motivo de la tercera edición, en 1957, de Hombres y épocas del Paraguay, una de las obras clásicas de Bray en la que compendia sus opiniones sobre la vida y actuación del mariscal López (tópicos que había estudiado en Solano López, soldado de la gloria y del infortunio, de 1946).

Se trata de un documento que podría asemejarse a un pequeño estado de la cuestión sobre los derroteros de la historiografía paraguaya durante medio siglo. Pastore plantea la necesidad de realizar una profunda revisión de la misma con el propósito de desenmascarar la interpretación de Juan O’Leary sobre el pasado guaraní (que se había transformado en uno de los referentes legitimadores del régimen de Alfredo Stroessner). El análisis crítico de esta misiva revela información trascendente sobre el pensamiento de Pastore en relación a la escritura de la Historia y sobre los usos políticos del pasado (en el contexto de la producción de los intelectuales liberales en el exilio).

\section{HISTORIADORES LIBERALES Y ESCRITURA DE LA HISTORIA}

Entre las décadas de 1930 y 1950 Paraguay experimentó un conjunto de acontecimientos significativos como la Guerra del Chaco (1932-1935), la decadencia de la hegemonía del Partido Liberal, la emergencia del militarismo nacionalista (1936), la dictadura de Higinio Morínigo (1940-1948) y el advenimiento del stronato (1954). ${ }^{4}$

4 Sobre este período véase a Rivarola-Boccia Paz, Historia general del Paraguay; Rodríguez Alcalá, Ideología autoritaria; Telesca-Gómez Florentín, Historia del Paraguay. Nuevas perspectivas; Telesca, Historia del Paraguay; Paredes, Stroessner y el stronismo. 
Durante ese período la indagatoria sobre el pasado se dinamizó debido a los requerimientos político-diplomáticos generados por el diferendo limítrofe con Bolivia, la fundación del Instituto de Investigaciones Históricas (1937) y la creación de la Facultad de Filosofía de la Universidad Nacional de Asunción (1948). ${ }^{5}$ Fue, sin dudas, una etapa de "alta tensión historiográfica” que estuvo pautada por medidas que buscaban imponer una política de la memoria legitimadora de los regímenes de turno (decretos del 1 de marzo y del 14 de septiembre de 1936). La interpretación castrense, autoritaria y nacionalista de Juan O’Leary se transformó en dominante.

En ese contexto histórico y epistémico desarrollaron su labor un grupo de historiadores afines al Partido Liberal entre los que se destacaron Justo Pastor Benítez (1895-1963), Efraím Cardozo (1906-1973), Julio César Chaves (1907-1989), Antonio Ramos (1907-1984) y Carlos Pastore (1907-1996).

Se trató de un conjunto de intelectuales que compartían referentes ideológicos y generacionales. ${ }^{6}$ Todos pasaron por las aulas del Colegio Nacional de Asunción (varios integraron la promoción de bachilleres de 1925) y se formaron como abogados en la Universidad Nacional. Eran militantes activos del Partido Liberal. Participaron en la Guerra del Chaco realizando tareas de asesoramiento y apoyo logístico (la excepción fue Justo Pastor Benítez, quien ejercía funciones diplomáticas en Río de Janeiro). Practicaron el periodismo y desempeñaron cargos políticos y administrativos. Padecieron la experiencia del exilio a consecuencia de los acontecimientos y vaivenes políticos de la última etapa de la hegemonía del Partido Liberal. La mayoría fueron docentes en la Universidad Nacional de Asunción y en la Universidad Católica. Recibieron premios por su labor intelectual e integraron prestigiosas corporaciones académicas en el Paraguay y en el exterior.

Se dedicaron con intensidad al estudio de la Historia. Consideraban que la investigación del pasado era fundamental para explicar los problemas nacionales y desmitificar su uso ideológico. ${ }^{7}$ Puede aplicarse al conjunto una

5 Brezzo, “El Paraguay en cinco momentos historiográficos: retos y perspectivas”, pp. 74-75; Sansón Corbo, "El campo historiográfico en Paraguay en la primera mitad del siglo XX: condicionamientos y monopolio interpretativo” y “El ‘colegio invisible’ de la historiografía de la región platense entre las décadas de 1930 y 1950 ”.

6 Cf. Benítez, Bajo el alero asunceño; Monte de López Moreira, "Semblanza histórica y efervescencia de los años 40”; Velázquez, "Los estudios históricos en el Paraguay” y Breve historia de la cultura en el Paraguay.

7 Estudio de la Historia y acción política se confundían en la labor de aquellos intelectuales. En una misiva muy significativa y de carácter intimista, fechada en Asunción el 2 de enero de 1950, R. Antonio Ramos formula un largo análisis sobre la situación del Partido Liberal y sobre la necesidad de organizarlo, refiere en tono de crónica varios ejemplos de la inseguridad y la violencia que imperaban en Paraguay. Comenta sobre el final: "Estoy leyendo LA LUCHA DE LA TIERRA EN EL PARAGUAY. Muy interesante. Tan pronto como termine 
reflexión formulada por Carlos Pastore Olmedo en referencia a su padre, Carlos Pastore Goiburu:

La pasión por conocer las verdaderas causas de los dramas sufridos por nuestro país como nación [...], así como la pasión por la acción política... que permitieran avanzar y mejorar las situaciones de dependencia y las profundas desigualdades entre los paraguayos, no lo abandonaron nunca. [...] [En su producción se puede apreciar una clara] pasión por estudiar y conocer la historia, así como nuestra realidad social y económica para intentar cambiarla. ${ }^{8}$

Su formación inicial se procesó en el contexto de un habitus ${ }^{9}$ plural y abierto al tránsito de ideas que, necesariamente, debía colisionar con las interpretaciones de nacionalismo excluyente de Juan O’Leary, que proponían un relato autosustentable y esquemático.

Aunque no rehuyeron el estudio de la Guerra de la Triple Alianza o la reciente del Chaco, se ocuparon preferentemente de temas y problemas relacionados con la sociedad, la política, las relaciones internacionales y la economía. Algunos ensayaron abordajes de cierto cariz interdisciplinario para explicar la historia nacional.

Por residir largos años en ciudades como Río de Janeiro, Montevideo y Buenos Aires, pudieron generar vínculos con investigadores locales, frecuentar repositorios documentales, producir obras relacionadas con la historia de las relaciones exteriores de Paraguay. Resultan significativas, en este sentido, las reflexiones de Carlos Pastore, en una carta dirigida a R. Antonio Ramos, referidas a las indagatorias que éste realizaba en Brasil:

Te deseo éxitos en tus investigaciones históricas. Es una gran suerte que te hayan permitido meter la nariz en la colección Río Branco. No dudo que sabrás aprovechar la oportunidad que te brindaron para conocer muchos hechos

la lectura te enviaré el juicio” (carta de R. Antonio Ramos a Carlos Pastore, Asunción, 2 de enero de 1950, Colección Carlos Pastore, Academia Paraguaya de la Historia, caja 31). La indagatoria del pasado constituía -tanto para el autor citado como para sus correligionarios en el exilio- un imperativo intelectual y una exigencia de la militancia. No se trataba solamente de un ejercicio de reconstrucción erudita de acontecimientos y procesos, sino de una empresa patriótica.

8 Pastore Olmedo, "Semblanza biográfica del Dr. Carlos Pastore Goiburu”, p. 21.

9 La categoría "habitus" fue definida por Pierre Bourdieu. Se refiere a un "sistema de las disposiciones socialmente constituidas que, [...] son el principio generador y unificador del conjunto de las prácticas y de las ideologías características de un grupo de agentes”. Condiciona el tipo de comportamiento, las "prácticas", asumido por un individuo en un determinado campo. Tiende a producir (y a explicar) las prácticas objetivas de los agentes que participan en el "juego", y hacen que el campo funcione (Bourdieu, Campo de poder, campo intelectual. Itinerario de un concepto, 106). 
ignorados o mal presentados de nuestra historia. ¿ No encontraste algo sobre el papel que daban al Paraguay en la política colonizadora de América de Luis Felipe y Napoleón III ${ }^{10}$

El conocimiento y la vinculación personal con colegas del exterior le permitieron a este grupo de historiadores ingresar, en calidad de miembros correspondientes, a corporaciones como el Instituto Histórico y Geográfico de Brasil, el Instituto Histórico y Geográfico del Uruguay y la Academia Argentina de la Historia.

\section{EXILIOS, FUENTES EPISTOLARES Y REDES INTELECTUALES}

El itinerario bio-bibliográfico de Carlos Pastore plantea, entre otras cuestiones teórico-metodológicas, los temas del exilio y de la escritura de la historia en(-desde) el mismo. Tanto la obra como el epistolario del autor brindan abundantes insumos para reflexionar sobre la experiencia del extrañamiento y su influencia en la producción del intelectual. Se trata de cuestiones muy debatidas y que plantean múltiples abordajes cuya consideración trasciende los límites de este artículo. No obstante, resulta necesario formular algunas puntualizaciones al respecto.

La producción teórica sobre el tema del exilio es abundante y resulta inasible. De todos modos (y aunque cualquier consideración sobre la misma puede resultar arbitraria y discutible) pueden resultar de utilidad las perspectivas analíticas planteadas por Siegfried Kracauer - Historia. Las últimas cosas antes de las últimas cosas (2010)_, Enzo Traverso — La historia como campo de batalla. Interpretar las violencias del siglo XX (2012)- y Tony Judt —El peso de la responsabilidad (2014)_. Estos autores brindan interesantes insumos epistemológicos para considerar la relación entre la experiencia del exilio — como metáfora y como realidad- y sus condicionamientos en la producción intelectual en general y en la historiográfica en particular.

Existen múltiples estudios sobre la producción intelectual y sobre las experiencias de los autores en situaciones de ostracismo. Se trata de investigaciones referidas a contextos y épocas muy diversas. Como ejemplos pueden citarse los trabajos relacionados con la expatriación de historiadores republicanos españoles en 1939 o de latinoamericanos en la década de 1970 . Los mismos basculan entre la memoria de los protagonistas y los estudios

10 Carta de Carlos Pastore a R. Antonio Ramos [copia], Montevideo, 2 de marzo de 1946, Colección Carlos Pastore, Academia Paraguaya de la Historia, caja 31. 
específicos sobre sus itinerarios y producciones. Entre los primeros pueden mencionarse las obras del uruguayo Juan Oddone - Mirando atrás. Historia y Memoria (2013) - y las de los españoles Vicente Llorens - Memorias de una Emigración. Santo Domingo, 1939-1945 (1975) — y Javier Malagón — "Los historiadores y la Historia en el exilio" (1978). En referencia a los segundos se destacan los estudios vinculados con la situación argentina, en especial - y sin pretensiones de inventario - los de Carlos Astarita — "La investigación en Historia y la historia de la persecución permanente” (2003) —; Nora Pagano — “Las ciencias sociales durante la dictadura argentina (1976-1981)” (2004) —; Hugo Biagini, Hebe Clementi y Marilú Bou — Historiografía argentina: la década de 1980 (1996).

En el epistolario de Carlos Pastore se custodia una documentación muy valiosa relacionada con la historia política de los Estados de la Cuenca del Plata, con la militancia en el exilio, con su itinerario personal y el de sus compañeros liberales. Las misivas ilustran también sobre las condiciones de producción de conocimiento histórico en ese contexto.

Liliana Brezzo subraya que Pastore conservó "de manera ordenadísima” el intercambio de cartas con sus correligionarios. Sobresale "la nutrida correspondencia con Antonio Ramos, entre los años 1938 y 1952 y, del mismo rango cronológico, el intercambio con Julio César Chaves”. También se destaca "el prolongadísimo vínculo epistolar que cultivó con Efraím Cardozo, que se extendió entre los años 1940 y 1973”. La historiadora argentina acota que, si bien "el principal contenido de esos intercambios era la coyuntura política paraguaya”, las misivas "permiten recuperar también otro tipo de preocupaciones derivadas de un programa de carácter político-cultural”. ${ }^{11}$ Efectivamente, la correspondencia brinda pistas para conocer el funcionamiento y la estructura de los circuitos de intercambio, las estrategias utilizadas por los integrantes de la red para difundir sus producciones y sus conceptualizaciones sobre personajes y épocas de la historia paraguaya.

Se trata de un corpus heurístico fundamental en cuanto que permite calibrar, en su integralidad, el contenido de los intercambios con cada corresponsal. Puede considerarse, a vía de ejemplo, el siguiente fragmento de una carta de Pastore a Ricardo Ramos, referida a la publicación de la obra El Paraguay Independiente, de Efraím Cardozo:

Para terminar con la serie de informaciones, te diré que la aparición del libro del Dr. Efraím Cardozo [...] me produjo una gran satisfacción. Gracias a Pivel Devoto, que me facilitó un ejemplar, lo pude leer. Considero que el libro de

11 Brezzo, “Reconstruyendo a Carlos Pastore: objetivos para una biografía intelectual”, p. 45. 
Cardozo es un acontecimiento en la enseñanza de la historia del Paraguay, especialmente de la historia diplomática del país o de lo relacionado con la diplomacia. La bibliografía que trae da a todos los lectores la oportunidad de recurrir a las fuentes para la confirmación o rectificación de la posición histórica del autor. Pienso que éste es uno de los grandes servicios que el Dr. Efraím Cardozo puede prestar a la cultura nacional. ${ }^{12}$

También se encuentra información sobre la propia obra de Pastore, en particular sobre La lucha por la tierra en el Paraguay. En la correspondencia intercambiada con Antonio Ramos hay varias pistas sobre la publicación del libro y datos que revelan el pensamiento del autor en relación a la historia paraguaya. Los indicios sugieren que en marzo de 1948 la obra estaba culminada. Pastore había sondeado la posibilidad de publicarlo en Fondo de Cultura de México o en un apartado de la Revista Histórica de Montevideo (dirigida por Juan Pivel Devoto). Informaba cotidianamente a sus corresponsales sobre los progresos de la investigación. Ramos se mostraba interesado en saber “¿cuándo sale tu otro libro sobre la cuestión de tierras?”; consideraba que la "obra va a causar sensación y tendrá honda repercusión en el Paraguay”. ${ }^{13}$ Finalmente la edición se canalizó por la editorial “Antequera”, creada por el mismo Pastore, "en memoria del revolucionario comunero”, como recuerda Liliana Brezzo. ${ }^{14}$

La aparición del libro fue aplaudida por Ramos. Lo consideró "un valioso servicio" a la "cultura liberal” y a "la patria”, así "se honra a la tierra nativa y se contribuye a su enaltecimiento”. ${ }^{15}$ El autor proyectaba en la obra de Pastore sus propias convicciones sobre la Historia en cuanto instrumento efectivo para la redención nacional en tiempos de autoritarismo.

\section{Carlos Pastore y “El general de la Virgen ESPADA”}

En la correspondencia intercambiada entre Carlos Pastore y los corresponsales con quienes compartía el interés por el estudio del pasado se pueden encontrar importantes pistas para el conocimiento de la historiografía paraguaya. Con frecuencia se descubren comentarios heurísticos, reflexiones sobre la importancia del conocimiento histórico para la acción política, refe-

12 Carta de Carlos Pastore a R. Antonio Ramos [copia], Montevideo, 5 de agosto de 1949, Colección Carlos Pastore, Academia Paraguaya de la Historia, caja 31.

13 Carta de R. Antonio Ramos a Carlos Pastore, Buenos Aires, 8 de marzo de 1949, Colección Carlos Pastore, Academia Paraguaya de la Historia, caja 31.

14 Brezzo, "Reconstruyendo a Carlos Pastore: objetivos para una biografía intelectual”, p. 50.

15 Carta de R. Antonio Ramos a Carlos Pastore, Asunción, 5 de diciembre de 1949, Colección Carlos Pastore, Academia Paraguaya de la Historia, caja 31. 
rencias a la producción de los interlocutores (o a la de otros autores), datos para conocer la trazabilidad de ciertas obras (proceso de creación, circulación y recepción de libros y artículos) y precisiones vinculadas a acontecimientos, personas o etapas de la historia de su país.

Ubicada en ese contexto, la misiva remitida al coronel Arturo Bray en 1959 — con motivo de la tercera edición de su libro Hombres y épocas del Paraguay (1957) — ${ }^{16}$ es una pieza única, tanto por su extensión como por su calado heurístico y epistemológico.

Arturo Bray era un prestigioso y polémico militar paraguayo. En Hombres y épocas del Paraguay presenta al mariscal López como "una figura de imponentes dimensiones, digna de ser estudiada y considerada con un criterio amplísimo, que abarque mucho de justicia y no poco de generosidad". ${ }^{17}$ No fue "ni genio ni monstruo". Para comprenderlo cabalmente es necesario ubicarlo en su época y aceptarlo "como el conductor de nuestro ejército en un momento decisivo de nuestra historia, identificándolo, de una vez por todas, con la causa nacional". ${ }^{18}$

Bray justifica los errores estratégicos de López en función de que había llegado al generalato "más por derecho de sucesión y circunstancias fortuitas, que por méritos adquiridos". Careció de "maestros en el arte militar", fue un "autodidacta", su experiencia castrense se redujo "a los períodos, más o menos largos, en que ejerció el mando del ejército nacional". ${ }^{19}$ Describe la secuencia de hechos que provocaron su muerte como un asesinato, "no de otra manera merece calificarse el repudiable acto de ultimar a un hombre herido, agonizante, debatiéndose en el momento final de su existencia". ${ }^{20}$ Valora su sacrificio como un martirio en pro de la patria. Gracias a su ejemplo el Paraguay vive "justificado y santificado" por sus "últimas palabras, y porque con ellas - a las puertas de la muerte- nueva vida" ${ }^{21}$ había dado.

La carta dirigida por Pastore a Bray, en 1959, no es una misiva tradicional. El jurista e historiador critica la interpretación del coronel sobre la figura de López. Cuestiona la oportunidad estratégica de la misma, evalúa la

16 La obra tenía dos ediciones previas en Buenos Aires.

17 Bray, Hombres y épocas del Paraguay. El Dictador. Don Carlos Antonio, El Mariscal. Caballero. Escobar. Egusquiza. Gondra. E. Ayala, p. 65.

18 Bray, Hombres y épocas del Paraguay. El Dictador. Don Carlos Antonio, El Mariscal. Caballero. Escobar. Egusquiza. Gondra. E. Ayala, p. 65.

19 Ibíd., p. 72.

20 Ibíd., p. 91.

21 Ibíd., p. 92. 
historiografía paraguaya de las seis últimas décadas y plantea cómo cree que debería escribirse. ${ }^{22}$

Es un texto complejo y extenso, de diez fojas, en el que se pueden identificar tres dimensiones discursivas: a) una estrictamente histórica —referida a la consideración de los hechos "objetivos" que pautaron el devenir nacional paraguayo-, b) otra historiográfica — vinculada con los relatos sobre el pasado — que informa sobre c) la política de la memoria — la utilización de los hechos y del relato en función de las contiendas partidarias e ideológicas del presente- . Pastore navega entre ellas, las problematiza y las contrasta. Denuncia el uso político de la Historia y esboza los lineamientos de lo que considera un ejercicio responsable y serio de la misma.

Es necesario tener en cuenta el lugar de enunciación de Pastore: un político e intelectual que luchaba desde el exilio contra el autoritarismo imperante en su país — de Higinio Morínigo primero, de Alfredo Stroessner después - en el marco de un Partido con dificultades para organizarse.

Identifica dos maneras de "escribir historia" en Paraguay. Una practicada por investigadores que procuraban documentarse y evaluar honestamente las alternativas del devenir. Otra cultivada por sedicentes historiadores que elaboraban textos más próximos a la novela que a la reconstrucción certera del pretérito. Evita definirlas, no utiliza calificativos, sencillamente las caracteriza apelando a un juego de contrastes de carácter político, epistémico y estético.

La primera "describe épocas, hechos, costumbres, deduce consecuencias y enjuicia acontecimientos y hombres”. ${ }^{23}$ Es significativa la utilización del verbo "describir" para referir la función del conocimiento histórico por parte de un autor que procede de manera analítica en sus producciones. En realidad, por lo menos es lo que se aprecia en La lucha por la tierra en el Paraguay, la descripción es un primer paso, una valoración de superficie, de hechos, costumbres y períodos, que permite, en segunda instancia, comprender los procesos y deducir consecuencias.

22 Debe destacarse que las convicciones historiográficas de Pastore eran compartidas por sus correligionarios liberales. Justo Pastor Benítez, por ejemplo (un lector entusiasta de Pastore), lo estimulaba a continuar con sus investigaciones para realizar una historia social y económica "que supere a esa crónica de gobernadores y de anécdotas personales y de choques de caballería”, porque "es hora que el Paraguay produzca los ensayos que se estila en el continente” (carta de Justo Pastor Benítez a Carlos Pastore. Río de Janeiro, 7 de octubre de 1952, Colección Carlos Pastore, Academia Paraguaya de la Historia, caja 29). Estas reflexiones referían de alguna manera al estancamiento de la historiografía paraguaya en relación con las de los Estados vecinos. Las expone un autor que, por su prolongada residencia carioca, tenía conocimiento de la producción brasileña en ciencias sociales y que tenía vínculos de amistad con Gilberto Freyre.

23 Carta de Carlos Pastore a Arturo Bray [copia], Montevideo, 1959, Colección Carlos Pastore, Academia Paraguaya de la Historia, caja 32, f. 1. 
Quien concibe la historia de esta forma no tiene pruritos en enjuiciar personas y actitudes. Se trata de una responsabilidad ante el lector, un imperativo ético en aras de la exactitud y de la verdad. Este historiador "hace escuela, dicta cátedra, toma partido". Procede con base en criterios definidos, "hace su labor dentro de la verdad que le aporta la documentación a que ha echado mano y estaba a su alcance". ${ }^{24}$

Pastore era consciente de la relatividad de la "verdad histórica", no sólo por preceptiva epistémica, sino con base en los condicionamientos a los que estaban sometidos los —en su concepto- verdaderos historiadores. Éstos, en función de las limitaciones objetivas impuestas por la situación del exilio y/o por el hecho de actuar en los márgenes de la inteligentzia, no podían acceder a los fondos documentales necesarios para el ejercicio de su tarea. $\mathrm{Si}$ bien considera que los cultores mayoritarios de esta línea historiográfica pertenecen al Partido Liberal, reconoce una tradición de intelectuales honestos que trasciende a esa colectividad.

La segunda forma de escribir historia era más literatura que conocimiento certero del pretérito. Sus cultores procuraban el preciosismo estilístico en lugar de la precisión heurística. Cuidaban la forma sin referir el fondo de los problemas estructurales que ralentizaban la evolución institucional, cultural y política de Paraguay. Procedían de esa manera con la intención de no perjudicar su "interés personal" (político, familiar o de "librería"). Bastardeaban la indagatoria del pasado, se limitaban a narrarlo en función del gusto y la moda imperante en el presente; atribuían valores de grandeza, heroísmo y patriotismo a ciertos personajes que inspiraban, en determinado momento, "la corriente política gobernante en el país". ${ }^{25}$ Ese proceder les aseguraba honores, cargos, la edición oficial de sus producciones y la probable erección de "un busto en su honor, no importa que sea de barro y que esté destinado a desaparecer y a convertirse en lo que fue, arena". ${ }^{26}$

Es obvio que Pastore se refiere, sin mencionarlo, a Juan O'Leary, quien en 1955 había obtenido la glorificación en vida con la inauguración de un busto en su homenaje, en pleno centro de Asunción, por iniciativa del general Alfredo Stroessner.

A falta de definiciones explícitas de Pastore, me atrevo a denominar "historia documental" e "historia literaria" a esas dos formas de referir los anales del Paraguay. El autor dibuja los perfiles de ambas vertientes en un

24 Ibíd.

25 Carta de Carlos Pastore a Arturo Bray [copia], Montevideo, 1959, Colección Carlos Pastore, Academia Paraguaya de la Historia, caja 32, f. 3.

26 Ibíd. 
juego de claroscuros: ignorada, clandestina, "legionaria” y vituperada la primera; promocionada, oficial patriótica y glorificada la segunda.

Se plantea una crítica severa sobre la persona y la obra de O’Leary, en especial la "divinización" de Francisco Solano López. Su "ditirambo es tan febricitante" que pierde la dimensión histórica. Coloca al Mariscal por encima de las personalidades más destacadas de América y Europa.

La recreación de la "gesta” de López por parte de O’Leary es ficcionada, ahistórica, pues lo que presenta como "incalculables méritos" son falacias que contribuyen a ocultar la realidad (que convirtió a "su patria en el cementerio de un millón de cadáveres” y la dejó “deshecha, desmembrada, hambreada, prostituida y desunida, para siempre quizás desunida espiritualmente"). ${ }^{27}$ Se contrasta la ficción de O’Leary sobre el Mariscal, con los testimonios de los cronistas contemporáneos (Juan Crisóstomo Centurión, Francisco Isidoro Resquín, entre otros).

Pastore reconstruye el itinerario de O'Leary. Destaca que "habiendo empezado su vida como liberal tiranófobo, notó que por esos senderos no iba a alcanzar notoriedad", porque "hay gente que no pudiendo obtener bienestar y popularidad por la línea recta y con la verdad, los medran por la línea quebrada de la simulación y del atraco". ${ }^{28}$ Contrasta su proceder con el de José Segundo Decoud y Cecilio Báez. Evoca el largo proceso de construcción del "lopizmo" realizado por O’Leary, desde comienzos del siglo, en una acción propagandística e ideológica que engatusó al pueblo y fue funcional a los intereses de la casta militar.

Se reconoce, con pesar, que la acción de O’Leary fue persistente y tenaz. Durante más de cinco décadas predicó incansablemente, desde "la cátedra, el libro, la prensa, la diplomacia, la diaria tertulia, ganando adeptos (y engañando incautos)". ${ }^{29}$ Procedió con audacia, sin subterfugios, convencido de que a las masas había que hablarles con energía y convicción, sin dejar lugar a dudas. Su estrategia contrastaba notoriamente con la de aquellos intelectuales que procuraban persuadir con argumentos académicos en tertulias de salón y que llegaban, por tanto, a un público restringido.

La mentira gritada por O’Leary terminó transformándose en verdad. La convicción de sus enunciados - de carácter performativo- convirtió al tirano López en símbolo excelso de heroicidad y al "cretinismo" del pueblo paraguayo — como lo había definido Báez- en martirio colectivo y epopeya nacional.

29 Ibíd., f. 5. 
Los gobernantes paraguayos terminaron identificándose con la figura de López y aplicando sus métodos para dominar y embrutecer al pueblo. Incluso algunos “escritores liberales” fueron seducidos por el lopizmo de O’Leary - o ponían medias tintas a la hora de evaluar la acción del tirano-, no tanto por convicción, sino por temor a la "muerte civil” 30 que suponía contradecir la opinión dominante en el ejército y en el gobierno. Entre esos autores ubica, con matices, a Justo Pastor Benítez, Julio César Chaves y Efraím Cardozo, entre otros.

La exposición de Pastore constituye un manifiesto en contra de la política de la memoria motorizada por O’Leary y oficializada desde 1936. Intenta sacudir a sus correligionarios para que griten la verdad y contradigan el discurso nacionalista autoritario pues, de no hacerlo, se perdería mucho más que la verdad histórica. Se esfumaría la esperanza de transformar un estado de situación que, en 1959, parecía muy comprometido para el Partido Liberal.

Si no había una reacción, que necesariamente debía ser histórica y política, la fábrica de héroes seguiría creando mitos. Posiblemente "dentro de veinte años Higinio Morínigo será un héroe resplandeciente, mientras las juventudes narcotizadas pregunten quién fue el Mariscal Estigarribia”. ${ }^{31}$

Interpela directa y enfáticamente a Artur Bray por la "indecisión en sus libros para decir la verdad desnuda”. ${ }^{32}$ Es un cuestionamiento leal en lo político y fundado en lo historiográfico. Ubica, en primera instancia, el "lugar de enunciación” del coronel: un hombre íntegro, honesto, sin ambiciones políticas, dedicado en el exilio bonaerense a la labor periodística e histórica. Podría, a partir de estas circunstancias, haberle dicho “a las juventudes la verdad desnuda sobre ciertos héroes que sus libros retratan con indulgencia

31 Carta de Carlos Pastore a Arturo Bray [copia], Montevideo, 1959, Colección Carlos Pastore, Academia Paraguaya de la Historia, caja 32, f. 5.

32 Ibíd., f. 6. Considero de relevancia consignar que, en una carta de Pastore dirigida a Justo Pastor Benítez (en referencia a un prólogo que éste le pidió para una obra vinculada a Estigarribia), se puede apreciar con total claridad, la relación entre conocimiento histórico y militancia política, tal como la entendían los historiadores del Partido Liberal: "Con mucho gusto le enviaré el prólogo a las Memorias de Estigarribia antes de su publicación, para que Ud. lo corrija. Hasta la fecha no he comenzado a escribir, porque me falta madurar el criterio histórico sobre algunos puntos. El material es muy abundante y no es fácil la coordinación de tantos elementos de juicio. Además, me falta todavía una que otra información documental. Como Ud. sabe, deseo dar al trabajo un sentido político constructivo, pero que sea al mismo tiempo, un homenaje a la verdad histórica, a la memoria de Estigarribia y a la acción de nuestro partido. No creo que la tarea sea difícil, pero sí que requiere tiempo. Sus indicaciones y consejos me serán muy útiles, al mismo tiempo que sus informaciones sobre los hechos principales del gobierno de Estigarribia después y antes del golpe de estado del 18 de Febrero" (carta de Carlos Pastore a Justo Pastor Benítez [copia], Montevideo, 7 de octubre de 1952, Colección Carlos Pastore, Academia Paraguaya de la Historia, caja 29). 
que se hace sospechosa para más de un malicioso". ${ }^{33}$ Los personajes en cuestión eran los López, Caballero y Escobar, entre otros. Formula varias observaciones sobre los méritos que atribuye a unos y niega a otros. El verdadero centro de la crítica es el Mariscal López.

Pastore enumera prolija y críticamente los tópicos más polémicos de la heroificación del personaje. Los cuestiona con precisión quirúrgica. Se detiene, en particular en la actitud del Mariscal hacia el General Díaz. Pone un manto de dudas sobre las verdaderas intenciones de López cuando le encomendó una misión subalterna, que finalmente le costaría la vida. Ése y otros temas deberían ser investigados por Bray con el objetivo de develar la verdad. Haría, de esta forma, "un gran servicio a las juventudes civiles y militares” 34 al desnudar las miserias éticas y los errores estratégicos del "general de la virgen espada”.35

Desafía a Bray para que demuestre que “además de fatuo, López era un inexperto en materia guerrera. Jamás él hizo uso de su pistola. Su espada fue virgen de toda virginidad. No la usó ni en sus mocedades, ni una sola vez, en cinco años de lucha”. ${ }^{36}$ Plantea que la sedicente epopeya de López y su pueblo en la etapa final de la guerra fue, en realidad, "locura y crimen”, ${ }^{37}$ causado por un desequilibrado que tenía pavor a la muerte.

A Pastore le preocupaba no sólo la figura de López, sino también su “sistema” — recreado por O’Leary_, que hizo carne en políticos y militares. El país

del 1908 a esta parte vive bajo la filosofía y la mística lopista, [...] filosofía de la fuerza, de la dictadura, de la crueldad, del Hombre-Estado. [...] mientras Francia, don Carlos y Solano López sean los arquetipos del gobernante lleno de virtudes y carente de culpa, ha de ser difícil instaurar y hacer sentir al pueblo lo que es, cómo es y cómo debe practicarse la democracia [...]. Como en la Alemania de Hitler, el virus es general y se ha infiltrado en todos los estratos sociales. ${ }^{38}$

Más culpables que O’Leary eran los intelectuales liberales, por no combatirlo con firmeza. "Y de esta suerte, hoy, en 1959, seguimos, en cierto

33 Ibíd.

34 Carta de Carlos Pastore a Arturo Bray [copia], Montevideo, 1959, Colección Carlos Pastore, Academia Paraguaya de la Historia, caja 32, f. 7.

35 Ibíd.

36 Ibíd., f. 8.

37 Ibíd.

38 Ibíd., f. 10. 
modo, mandados y gobernados por Francisco Solano López a través de su espíritu". ${ }^{39}$

\section{CONCLUSIÓN}

Entre las décadas de 1930 y 1950, Paraguay experimentó un período de alta densidad historiográfica. La imposición de un relato hegemónico de cariz nacionalista mediatizó la producción y relegó a los autores liberales a los márgenes del sistema. Formados en un habitus plural y abierto, necesariamente debieron colisionar con el nacionalismo excluyente de Juan O’Leary, que había entronizado a Francisco Solano López como héroe máximo de la nación y espejo de las futuras generaciones.

El epistolario de Pastore contiene valiosa información sobre las formas, los autores y las tendencias de la escritura de la historia paraguaya (dentro del territorio nacional y en el contexto del destierro). En la intimidad del contacto reservado que se canalizaba a través de la correspondencia, el ilustre exiliado y sus corresponsales exponen con absoluta sinceridad sus convicciones más profundas en relación a los usos del pasado con propósitos políticos. Revelan, además, las dificultades para investigar, en especial por las limitaciones para acceder a las insumos heurísticos y a los recursos bibliográficos. Estos inconvenientes los motivarán a establecer contactos y generar redes - entre ellos y con colegas de otras nacionalidades - a efectos de viabilizar las indagatorias.

En la misiva estudiada, Pastore formula una dura crítica sobre la interpretación de la historia realizada por Bray. Consideraba que la misma contribuiría a consolidar la política de la memoria del gobierno implementada por el régimen autoritario del general Alfredo Stroessner. Se perfilan en este punto las tres dimensiones discursivas del alegato epistolar de Pastore en torno a la construcción artificiosa del imaginario colectivo que, desde principios del siglo XX, se estaba procesando en Paraguay.

La militancia política del exiliado liberal tenía en la Historia uno de sus baluartes fundamentales. Apelaba a la inteligencia de un referente ético del Paraguay contemporáneo — Bray — para que analizara de manera objetiva la peripecia vital de los personajes deformados por O’Leary (dimensión histórica). Recurría para ello a una crítica de sus relatos e interpretaciones (dimensión historiográfica). Esperaba de su interlocutor una corrección de rumbo con el propósito de incrementar el capital argumentativo en las contiendas políticas e ideológicas de su época (dimensión de la política de la historia). 


\section{BIBLIOGRAFÍA}

Astarita, Carlos, "La investigación en Historia y la historia de la persecución permanente”, Razón y Revolución, 2003, pp. 189-198.

Benítez, Justo Pastor, Bajo el alero asunceño, Río de Janeiro, Ministerio de Educación y Cultura, 1955.

Biagini, Hugo, Clementi, Hebe-Bou, Marilú, Historiografía argentina: la década de 1980, Buenos Aires, Editores de América Latina, 1996.

Bourdieu, Pierre, Campo de poder, campo intelectual. Itinerario de un concepto, Buenos Aires, Montressor, 2002.

Bray, Arturo, Armas y letras. Memorias, Asunción, Ediciones Napa, 1981, tres tomos.

- Hombres y épocas del Paraguay. El Dictador. Don Carlos Antonio, El Mariscal. Caballero. Escobar. Egusquiza. Gondra. E. Ayala, Buenos Aires, Ediciones Nizza, 1957, tercera edición.

Solano López. Soldado de la gloria y del infortunio, Asunción, El Lector 2011 [Primera edición: Buenos Aires, 1946].

Brezzo, Liliana, "El Paraguay en cinco momentos historiográficos: retos y perspectivas”, Casal, Juan Manuel y Whigham, Thomas (eds.), Paraguay: el nacionalismo y la Guerra. Actas de las Primeras Jornadas Internacionales de Historia del Paraguay en la Universidad de Montevideo, Asunción, Universidad de Montevideo-Servilibro, 2009 pp. 61-78.

"Reconstruyendo a Carlos Pastore: objetivos para una biografía intelectual”, Brezzo, Liliana - Boccia Romañach, Alfredo - Rivarola, Domingo (eds.), Carlos Pastore Goiburu. 65 años de "La lucha por la tierra en el Paraguay”. Edición de homenaje, Asunción, Centro Paraguayo de Estudios Sociológicos-Academia Paraguaya de la Historia, 2014, pp. 37-67.

"Institucionalizar la escritura del pasado. La Academia Paraguaya de la Historia (1937-1965)”, Anuario de Estudios Americanos, vol. 73, núm. 1, 2016, pp. 291-317. DOI: https://doi.org/10.3989/aeamer.2016.1.10

Colección Carlos Pastore (Epistolario), Academia Paraguaya de la Historia, cajas 31-32.

Judt, Tony, El peso de la responsabilidad, Buenos Aires, Taurus, 2014.

Kracauer, Siegfried, Historia. Las últimas cosas antes de las últimas cosas, Buenos Aires, Las Cuarenta, 2010.

Llorens, Vicente, Memorias de una Emigración. Santo Domingo, 1939-1945, Barcelona, Ariel, 1975.

Malagón, Javier, “Los historiadores y la Historia en el exilio”, en Abellán García González, José Luis (coord.), El exilio español de 1939, vol. 5, Madrid, Taurus, 1978, pp. 245-354. 
Monte de López Moreira, Mary, "Semblanza histórica y efervescencia de los años 40”, Carrón, José María y otros, La década del '40 (Historia, educación, pensamiento y literatura), Asunción, Criterio Ediciones, 2006, pp. 25-90.

Pagano, Nora, "Las ciencias sociales durante la dictadura argentina (1976-1981)”, en Devoto, Fernando y Pagano, Nora, La historiografía académica y la historiografía militante en la Argentina, Buenos Aires, Biblos, 2004, pp. 159-169.

Paredes, Roberto, Stroessner y el stronismo, Asunción, Servilibro, 2011.

Pastore, Carlos, La lucha por la tierra en el Paraguay, Montevideo, Antequera, 1949.

Pastore Olmedo, Carlos, "Semblanza biográfica del Dr. Carlos Pastore Goiburu”, Brezzo, Liliana; Boccia Romañach, Alfredo -y Rivarola, Domingo (eds.), Carlos Pastore Goiburu. 65 años de "La lucha por la tierra en el Paraguay”, Edición de homenaje, Asunción, Centro Paraguayo de Estudios Sociológicos - Academia Paraguaya de la Historia, 2014, pp. 13-35.

Rivarola, Milda y Boccia Paz, Alfredo, Historia general del Paraguay, Asunción, Fausto Ediciones, 2013, t. III.

Rodríguez Alcalá, Guido, Ideología autoritaria, Asunción, Servilibro, 2007.

Sansón Corbo, Tomás, "El campo historiográfico en Paraguay en la primera mitad del siglo xx: condicionamientos y monopolio interpretativo", Historiografías, núm. 13, 2017, pp. 55-73.

DOI: https://doi.org/10.26754/ojs_historiografias/hrht.2017132351

, "El 'colegio invisible' de la historiografía de la región platense entre las décadas de 1930 y 1950”, Navegamérica, núm. 19, 2017, pp. 1-24.

Telesca, Ignacio y Gómez Florentín, Carlos (eds.), Historia del Paraguay. Nuevas perspectivas, Asunción, Servilibro, 2018.

Telesca, Ignacio (coord.), Historia del Paraguay, Asunción, Taurus, 2010.

Traverso, Enzo, La historia como campo de batalla. Interpretar las violencias del siglo XX, Buenos Aires, Fondo de Cultura Económica, 2012.

Velázquez, Rafael Eladio, “Los estudios históricos en el Paraguay”, Estudios Americanos, vol. XI, núm. 52, 1956, pp. 65-79.

, Breve historia de la cultura en el Paraguay, Asunción, Centro de Publicaciones de la Universidad Católica "Nuestra Señora de la Asunción”, 1999 (reimpresión). 